\title{
Inhibitory effects of an aqueous extract of Clitoria ternatea flower on $\alpha$-glucosidase during in-vitro wheat starch digestion
}

This abstract was awarded the Student prize.

Phenolic compounds in plants inhibit $\alpha$-glucosidase, reducing carbohydrate absorption and contributing to anti-diabetic activity ${ }^{(1)}$, particularly anthocyanins from coloured fruit and vegetables such as berries ${ }^{(2)}$ and black and purple carrots ${ }^{(3)}$. The aim of this study was to evaluate inhibition behaviours of an extract from the blue $C$. ternatea flower against $\alpha$-glucosidase during in-vitro wheat starch digestion i.e. the potential of the flower extract to modulate starch digestion in a bid to reduce postprandial hyperglycaemic response.

Inhibition of an aqueous extract of dried $C$. ternatea flowers, at different concentrations, against $\alpha$-glucosidase was determined according to the method of Sui et al $^{(4)}$ with minor modifications. In Eppendorf tubes, at each extract concentration, aliquots were mixed with the extract, $0.5 \mathrm{mg} / \mathrm{mL} \alpha$-glucosidase, $40 \mathrm{mg} / \mathrm{L}$ calcium chloride, and distilled water to $712 \mu \mathrm{L}$, then incubated at $37^{\circ} \mathrm{C}$ for $15 \mathrm{~min}$ for the enzyme to interact with the extract. Aliquots were made up to a $750 \mu \mathrm{L}$ reaction solution with $1 \mathrm{mg} / \mathrm{mL}$ gelatinised starch solution and incubated at $37^{\circ} \mathrm{C}$ for 5 min to simulate starch digestion. Exactly $100 \mu \mathrm{L} \mathrm{3,5-dinitrosalicylic} \mathrm{acid} \mathrm{reagent} \mathrm{solution}$ was added to each tube, heated for $10 \mathrm{~min}$ in boiling water, then cooled for $10 \mathrm{~min}$ in an ice bath; glucose concentration was then measured. Experiments were repeated with $C$. ternatea extract at $3 \mathrm{mg} / \mathrm{mL}$ and differing starch concentrations; $0.5-2 \mathrm{mg} / \mathrm{mL}$. All experiments were repeated in triplicate.

Results showed decreases in glucose liberated and increases in \%inhibition, after 5 min digestion, as concentrations of $C$. ternatea extract increased. Around $80 \%$ inhibition was reached at $5 \mathrm{mg} / \mathrm{mL}$ C. ternatea extract. Significant statistical differences $(\mathrm{p}<0.001)$ were found between the means of $C$. ternatea extract groups as determined by one-way ANOVA. Tukey post hoc tests showed that mean glucose liberated between each concentration was statistically significantly lower as concentration increased $(p<0.05)$, except between concentrations 3 and $4 \mathrm{mg} / \mathrm{mL}$, where the difference found was not statistically significant $(\mathrm{p}=0.421)$. Inhibition activity of $C$. ternatea extract against $\alpha$-glucosidase was found to be uncompetitive with $\mathrm{K}_{\mathrm{M}}=2.309 \mathrm{mg} / \mathrm{mL}, \mathrm{V}_{\mathrm{MAX}}=0.346 \mathrm{mgmin}{ }^{-1}$ and $\mathrm{IC}_{50}=2.315 \mathrm{mg} / \mathrm{mL}$.

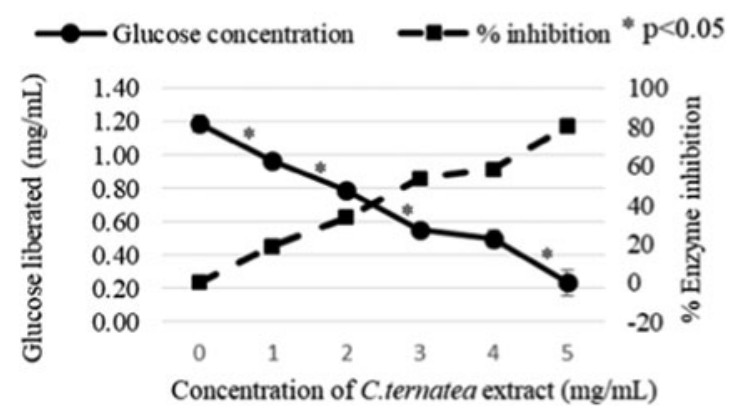

Fig. 1. Effect of C.ternatea extract on $\%$ inhibition of $\alpha$-glucosidase.

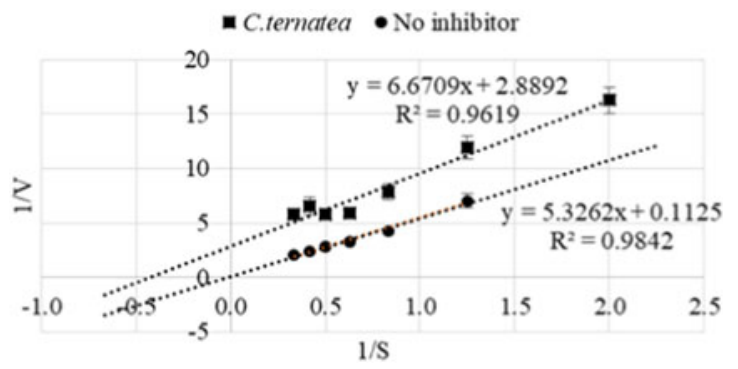

Fig. 2. Lineweaver-Burk plot; with and without C.ternatea extract to assess type of inhibiton against $\alpha$-glucosidase.

These results suggest that $C$. ternatea extract has potential to be utilised to prepare functional foods and/or nutraceuticals to help control postprandial hyperglycaemic response therefore, could be used to treat, and reduce the risk of developing, Type 2 diabetes.

1. Lin D, Xiao M, Zhao J et al. (2016) Molecules 21, 1374.

2. Castro-Acosta M, Lenihan-Geels G, Corpe CP et al. (2016) P NUTR SOC 75, 342-355.

3. Esatbeyoglu T, Rodríguez-Werner M, Schlösser A et al. (2016) J Agric Food Chem 64, 5901.

4. Sui X, Zhang Y, Zhou W (2016) J Funct Foods 21, 50-57. 